(2) Open Access Full Text Article

\title{
Drug-related problems in a sample of outpatients with chronic diseases: a cross-sectional study from Jordan
}

This article was published in the following Dove Press journal:

Therapeutics and Clinical Risk Management

17 February 2016

Number of times this article has been viewed

\author{
Sayer I Al-Azzam' \\ Karem H Alzoubi' \\ Salah AbuRuz ${ }^{2}$ \\ Qais Alefan' \\ 'Department of Clinical Pharmacy, \\ Faculty of Pharmacy, Jordan University \\ of Science and Technology, Irbid, \\ ${ }^{2}$ Department of Biopharmaceutics \\ and Clinical Pharmacy, Faculty of \\ Pharmacy, University of Jordan, \\ Amman, Jordan
}

\begin{abstract}
Optimization of drug therapy and preventing drug-related problems (DRPs) are major factors to improve health care, reduce expenditure, and potentially save lives. This study aimed at describing the types, numbers, and frequencies of DRPs in the outpatient settings of a group of hospitals in Jordan. The study was set in the cardiology, endocrine, and respiratory outpatient clinics of five major hospitals in Jordan. Patients who visited the above clinics during the period from September 2012 to December 2013, were candidates for this study. Each included subject was fully assessed for DRPs by clinical pharmacists according to a specially designed and validated pharmaceutical care manual. The main outcome measures were the number and types of DRPs. Data were collected from 2,898 patients (mean age \pm standard deviation: $56.59 \pm 13.5$ years). The total number of identified DRPs was 32,348, with an average of 11.2 DRPs per patient. The most common DRPs were a need for additional or more frequent monitoring, a problem in patients' adherence to self-care activities or nonpharmacological therapy, and that the patient was not given instruction in or did not understand nonpharmacological therapy or self-care advice. The numbers of DRPs per patient in our sample were associated with older age ( $>57$ years), being unmarried, having an education level of high school or less, not having health insurance, and the presence of certain clinical conditions, including hypertension, diabetes mellitus, dyslipidemia, ischemic heart disease, cardiac catheterization, heart failure, and gout. In conclusion, implementation of clinical pharmacy services is a strategy to limit DRPs. Certain patient populations are more vulnerable to DRPs.
\end{abstract}

Keywords: drug-related problems, outpatient, hospital, Jordan

\section{Introduction}

For most diseases, drug therapy enhances health-related quality of life. ${ }^{1}$ However, inappropriate use of drugs may be harmful and could evoke side effects. ${ }^{2}$ Drug therapy is growing more complex, thus making appropriate patient management increasingly challenging. ${ }^{3}$ A drug-related problem (DRP), defined as a drug therapy problem, is any undesirable event experienced by a patient that involves, or is suspected to involve, drug therapy and that interferes with achieving the desired goals of therapy. ${ }^{4}$ Accordingly, in clinical medicine, a wide range of DRPs may arise. ${ }^{5}$ Optimization of drug therapy and preventing DRPs may save some of the health care expenditure, potentially save lives, and enhance patient's quality of life. ${ }^{6-8}$ Previous studies have largely addressed DRPs as a cause of hospitalization, ${ }^{6,9,10}$ and in elderly, ${ }^{7,11}$ ambulatory care, ${ }^{11-14}$ nursing homes, ${ }^{15}$ and hospitalized patients. ${ }^{16}$

DRPs have been identified as contributing to negative clinical and economic outcomes in several international health care systems such as the Netherlands, ${ }^{17}$ Denmark, ${ }^{18}$
Correspondence: Sayer I Al-Azzam

Department of Clinical Pharmacy, Faculty of Pharmacy, Jordan University of Science and Technology, Irbid 22I I0, Jordan

Tel +96227201000

Fax +96227201075

Email salazzam@just.edu.jo
Therapeutics and Clinical Risk Management 2016:12 233-239

(c) (1) (8) ( 2016 Al-Azzam et al. This worki is pulished and licensed by Dove Medical Press Limited. The full terms of this license are available at https//www.dovepress.com/terms.php

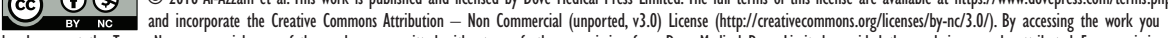
hereby accept the Terms. Non-commercial uses of the work are permitted without any further permission from Dove Medical Press Limited, provided the work is properly attributed. For permision for commercial use of this work, please see paragraphs 4.2 and 5 of our Terms (https://www.doveppess. com/terms.php).

233
Dovepress

http://dx.doi.org/10.2147/TCRM.S98165 you 
New Zealand, ${ }^{19}$ Qatar, ${ }^{12}$ and Saudi Arabia. ${ }^{20}$ In Jordan, a study aimed at describing DRPs of hospitalized patients in the internal medicine department of one hospital showed a mean DRP rate of 9.4 per patient. ${ }^{16}$ Another recently published study assessed DRPs in patients with chronic diseases who visited community pharmacies and reported a mean DRP rate of 4.1 per patient. ${ }^{21}$ However, there are no published large-scale studies describing DRPs in outpatient settings in Jordan. Such data could feed into decision making pertaining to reducing DRPs. This study aimed at describing DRPs in the outpatient settings of a group of hospitals that represent different sectors of the health care system in Jordan.

\section{Methods}

In this cross-sectional observational study, a sample of patients from five hospitals representing all sectors of health services, including public, private, and military hospitals, were assessed for DRPs. These hospitals were King Abdullah University Hospital and Princess Basma Teaching Hospital in Irbid, University of Jordan Hospital, Prince Hamzeh Hospital, and Al Bashir Hospital in Amman and Al-Karak Hospital at Al Karak city. These hospitals were chosen based on several criteria, including geographic location, being a major hospital in its area, and the type of health sector represented.

\section{Ethical approval}

The study protocol was approved by the institutional review boards of King Abdullah University Hospital, University of Jordan Hospital, and the Ministry of Health, Jordan, which oversees all the other three hospitals.

\section{Sample size}

Previous literature related to inappropriate drug use in Jordan indicated that the standard deviation (SD) for the number of identified DRPs was five. ${ }^{16,22}$ Based on this, the minimum required sample size to estimate the average number of DRPs within a confidence of $99 \%$ was calculated to be 94 / hospital/setting. The following equation was used: sample size $=(1.96 \times \mathrm{SD} /$ desired error ratio $){ }^{2}$

\section{Study subjects}

Patients who visited the cardiology, endocrine, and respiratory outpatient clinics during the period from September 2012 to December 2013 were invited to participate, and if they fitted the inclusion criteria, they were given a brief explanation about the study and asked to sign the informed consent form. Thus, informed written consent was obtained from all participants. The inclusion criteria were patients aged $>18$ years old, had at least one chronic medical condition, and received at least two medications, including all routes of administration, topical, inhaled, as needed, over the counter, etc. Patients with mental diseases and patients who did not speak Arabic or English language were excluded from the study.

\section{Definition and classification of DRPs}

The tool described in AbuRuz et al was used for the classification of DRPs. ${ }^{16,22}$ This classification system was previously evaluated for reproducibility, inter-rater agreement, content validity, and internal and external validities and was tested on $>200$ patients. ${ }^{16,22}$ All DRPs were identified by pharmacists $(n=5)$ who held a Doctor of Pharmacy degree and who were trained on the study protocol in a special workshop that was held by the principal investigator of the study. DRPs were evaluated to ensure uniformity of classification in Table 1 by

Table I Classification of DRPs among studied patients $(n=2,898)$

\begin{tabular}{|c|c|}
\hline DRP type & n (\%) \\
\hline A need for additional or more frequent monitoring & |3,498 (4I.73) \\
\hline $\begin{array}{l}\text { A problem in patients' adherence to self-care activities } \\
\text { or nonpharmacological therapy }\end{array}$ & $4,351(13.45)$ \\
\hline $\begin{array}{l}\text { The patient was not given instruction in or did not } \\
\text { understand nonpharmacological therapy or self-care advice }\end{array}$ & $4,002(12.37)$ \\
\hline $\begin{array}{l}\text { The patient was not given instruction in or did not } \\
\text { understand important information regarding his } \\
\text { medications }\end{array}$ & $3,373(10.43)$ \\
\hline $\begin{array}{l}\text { The patient requires additional combination therapy or } \\
\text { stepping up }\end{array}$ & $2,456(7.59)$ \\
\hline Drug use without an indication & $799(2.47)$ \\
\hline A need for consultation & $621(1.92)$ \\
\hline $\begin{array}{l}\text { Untreated conditions that require pharmacological or } \\
\text { nonpharmacological therapy }\end{array}$ & $595(1.84)$ \\
\hline Dosage regimen issue & $515(1.59)$ \\
\hline More effective drug is available & $444(1.37)$ \\
\hline A need for additional diagnostic test & $392(1.21)$ \\
\hline A problem in patients' adherence to medications & $344(1.06)$ \\
\hline The patient treatment should be stepped down & $316(0.98)$ \\
\hline Drug product not available & $133(0.41)$ \\
\hline Duplication & $97(0.30)$ \\
\hline Safety interactions issues & $81(0.25)$ \\
\hline $\begin{array}{l}\text { A current drug is contraindicated/unsafe for patient } \\
\text { condition and should be stopped, monitored, or replaced }\end{array}$ & $74(0.23)$ \\
\hline Safety dosage regimen issues & $54(0.17)$ \\
\hline A safer drug is recommended & $51(0.16)$ \\
\hline $\begin{array}{l}\text { The patient is at high risk of developing ADR and needs } \\
\text { monitoring or prophylaxis }\end{array}$ & $48(0.15)$ \\
\hline Efficacy interaction issue & $40(0.12)$ \\
\hline $\begin{array}{l}\text { Allergic reaction or an undesirable effect: are there } \\
\text { symptoms or medical problems that may be drug } \\
\text { induced }\end{array}$ & $27(0.08)$ \\
\hline Addiction or recreational drug use & $22(0.07)$ \\
\hline The chosen medication(s) is not (are not) cost-effective & $12(0.04)$ \\
\hline Avoidable adverse reaction & $3(0.01)$ \\
\hline
\end{tabular}

Abbreviations: DRPs, drug-related problems; ADR, adverse drug reaction. 
a panel of clinical pharmacists that included the study's main author and coauthors and other five clinical pharmacists. According to AbuRuz et al, ${ }^{22}$ DRPs were pooled under six main categories: indication, effectiveness, safety, knowledge, adherence, and miscellaneous. The indication category included the following two subcategories: unnecessary drug therapy (ie, the patient is receiving a medication for no valid medical indication) and untreated condition (ie, the patient has a medical problem that requires medication therapy but he/she is not receiving it). The efficacy category included four subcategories. First, more effective drug is available or recommended: the patient has a medication indication but he is not being treated properly with the most effective therapy. Second, the patient requires additional or combination therapy or stepping up because of actual or potential therapy failure or because of guidelines recommendation. Third, efficacy issues of dosage regimen: the patient has a medical problem that is being treated with too little of the correct medication because of a wrong dose, frequency, or duration. The patient may also have inappropriate dose regimen because of inappropriate timing or wrong dosage form. Finally, efficacy interactions issues: the patient has or is at risk of developing a medical problem or symptom that is the result of a drug-drug, drug-food, or drug-laboratory test interaction that reduces the efficacy of the drugs. The safety category included six subcategories. First, a current drug is contraindicated or unsafe for patient condition and should be stopped and monitored. Second, safer drug therapy is recommended. Third, the patient is at high risk of developing adverse drug reaction and needs monitoring or prophylaxis. Fourth, allergic reaction or undesirable effects: presence of symptoms or medical problems that may be drug induced. Fifth, safety dosage regimen issues: the patient has a medical problem that is being treated with too much of the correct medication because of a wrong dose, frequency, or duration. The patient may also have an inappropriate dose regimen because of inappropriate timing or wrong dosage form. Sixth, safety interactions issues: the patient has or is at risk of developing a medical problem or symptom that is the result of a drug-drug, drug-food, or drug-laboratory test interaction. The knowledge category included two subcategories. The patient was not given instruction in or did not understand important information regarding his or her medications (the purpose of his or her medication(s), how much, how and when to take it, what to avoid, how to prevent the side effect, and how to monitor his or her treatment). The patient was not given instruction in or did not understand nonpharmacological therapy or self-care advice (avoidance of risk factors, smoking, alcohol, diet, exercise, etc). The adherence category included two subcategories: problem in patient's adherence to medications (forget, skip, cannot afford, cannot swallow/administer drug, etc) and a problem in patients' adherence to self-care activities or nonpharmacological therapy. The miscellaneous category included four subcategories: a need for additional or more frequent monitoring, a need for additional diagnostic test, a need for consultation, and the chosen medication is not cost-effective.

\section{Procedure}

Patients were recruited by pharmacists who were involved in the study. Patients were approached at the physician office right after they finished their dialogue with the physician. Once a patient was recruited, he or she was fully assessed for DRPs by clinical pharmacists according to the following procedure: collecting patient's information using a specially designed and validated pharmaceutical care manual. ${ }^{22}$ Patient's information was collected from patient's medical file and patient interviewing to obtain information on patient's knowledge and adherence and by participating in medical rounds. Collected information was recorded on special paper-based forms that were prepared based on the pharmaceutical care manual. ${ }^{22}$ Patient's information was analyzed to identify DRPs utilizing an evidence-based approach $^{23}$ and by investigating laboratory data, assessing the achievement of treatment outcomes, and interviewing patients.

\section{Identifying DRPs}

A systematic approach was utilized in identifying DRPs. ${ }^{4}$ Effectiveness-related problems were identified through comparing patients' treatment with the most updated clinical practice evidence-based guideline recommendations. Appropriateness of dosing regimen was checked by comparing doses with evidence-based guidelines recommendations or using drug information references such as Lexicomp's Drug Information Handbook. ${ }^{4}$ Patients' clinical characteristics were taken into account when deciding about the appropriateness of dosage regimen. Adverse drug reactions were identified by conducting review of symptoms and by investigating patients' data for any possible adverse reaction related to patients' medications. ${ }^{4}$ Potential adverse drug reactions were also checked by identifying patients who were at risk but were not receiving prophylaxis (eg, patients' not receiving prophylaxis for non-steroidal anti-inflammatory drugs-induced ulcer). I-Facts (Facts and Comparisons Drug 
Interactions Facts) were used for identifying clinically important drug-drug interactions. ${ }^{4}$

\section{Data analysis}

Data were coded and entered into SPSS Version 19 (IBM Corporation, Armonk, NY, USA). Categorical data were expressed as numbers and percentage. Age and continuous data were expressed as mean $\pm \mathrm{SD}$. Unpaired $t$-test was used to compare the mean number of DRPs among patients according to demographic and health conditions (eg, hypertension and diabetes mellitus).

\section{Results}

Out of 3,112 patients, we collected data from 2,898 patients. Demographic data are shown in Table 2. The mean \pm SD of patients' age was $56.59 \pm 13.5$, and $\sim 40.1 \%$ of them were males. More than $90 \%$ of patients had health insurance. Additionally, $9.1 \%$ of patients suffered from drug allergy. Table 3 shows the clinical or disease characteristics of patients. Notably, $\sim 74 \%$ of the patients suffered from hypertension, $52.2 \%$ were diabetic, and $38.0 \%$ had dyslipidemia. Laboratory parameters of the studied sample are shown in Table 4.

The total number of identified DRPs was 32,348 with a mean \pm SD of 11.2 \pm 6.2 DRPs per patient. DRPs were classified into standard categories as shown in Table 1.

Table 2 Patient's demographic data $(n=2,898)$

\begin{tabular}{ll}
\hline Variable & $\begin{array}{l}\text { n (\%) or } \\
\text { mean } \pm \text { SD }\end{array}$ \\
\hline Age & $56.59 \pm 13.5$ \\
Sex & \\
Male & $1,162(40.1 \%)$ \\
Female & $1,724(59.5 \%)$ \\
Clinic type & \\
Cardiology & $1,523(52.5 \%)$ \\
Endocrine & $725(25.0 \%)$ \\
Respiratory & $650(22.5 \%)$ \\
Hospital & \\
King Abdulla University Hospital (KAUH) & $549(19.0 \%)$ \\
Princess Basma Teaching Hospital & $575(19.8 \%)$ \\
University of Jordan Hospital & $650(22.4 \%)$ \\
Prince Hamzeh Hospital & $501(17.3 \%)$ \\
Al Bashir Hospital & $218(7.5 \%)$ \\
Al-Karak Hospital & $402(13.9 \%)$ \\
Health insurance & \\
Yes & $2,652(91.5 \%)$ \\
No & $90(3.1 \%)$ \\
Allergy & \\
Yes & $264(9.1 \%)$ \\
No & $2,478(85.5 \%)$ \\
\hline Note: Due to missing
\end{tabular}

Note: Due to missing values, some numbers do not add up to $100 \%$. Abbreviation: SD, standard deviation.
Table 3 Clinical characteristics of patients $(n=2,898)$

\begin{tabular}{ll}
\hline Clinical variable & n (\%) \\
\hline Hypertension & $2,146(74.1)$ \\
Diabetes mellitus & $1,510(52.2)$ \\
Dyslipidemia & $1,100(38.0)$ \\
Ischemic heart disease & $846(29.2)$ \\
Cardiac catheterization & $80 \mathrm{I}(27.6)$ \\
Asthma & $608(21.0)$ \\
Heart failure & $261(9.0)$ \\
Cholecystectomy & $248(8.6)$ \\
Hypothyroidism & $178(6.1)$ \\
Gout & $144(5.0)$ \\
Chronic obstructive pulmonary disease & $117(4.0)$ \\
Renal impairment & $10 \mathrm{I}(3.5)$ \\
Coronary artery bypass graft & $76(2.6)$ \\
Rheumatoid arthritis & $64(2.2)$ \\
\hline
\end{tabular}

The most common DRPs were a need for additional or more frequent monitoring, a problem in patients' adherence to self-care activities or nonpharmacological therapy, and the patient was not given instruction in or did not understand nonpharmacological therapy or self-care advice. Other DRPs are also shown in Table 1. Associations of numbers of DRPs per patient with patient demographic and clinical conditions are shown in Tables 5 and 6 . Older patients ( $>57$ years), not married, having education of high school or less, and not having health insurance were associated with significantly more DRPs/patient. Hypertension, diabetes mellitus, dyslipidemia, ischemic heart disease, cardiac catheterization, heart failure, and gout were associated with significantly higher numbers of DRPs, whereas asthma and chronic

Table 4 Laboratory parameters of patients $(n=2,898)$

\begin{tabular}{|c|c|c|}
\hline Parameter & $\begin{array}{l}\text { Mean } \pm \text { standard } \\
\text { deviation (SD) }\end{array}$ & $\begin{array}{l}\text { Normal } \\
\text { range }\end{array}$ \\
\hline $\begin{array}{l}\text { Low density lipoprotein } \\
\text { (LDL; } \mathrm{mmol} / \mathrm{L} \text { ) }\end{array}$ & $3.05 \pm 1.09$ & $2.6-4.8$ \\
\hline $\begin{array}{l}\text { High density lipoprotein } \\
\text { (HDL; mmol/L) }\end{array}$ & $1.20 \pm 0.39$ & $0.9-1.5$ \\
\hline Cholesterol (mmol/L) & $4.94 \pm 1.28$ & $0.0-5.2$ \\
\hline Triglycerides (TG; mmol/L) & $2.07 \pm 1.43$ & $0.0-1.7$ \\
\hline Glucose (mmol/L) & $10.08 \pm 13.23$ & $4.1-5.9$ \\
\hline $\begin{array}{l}\text { Glycosylated hemoglobin } \\
\text { (AIC; \%) }\end{array}$ & $7.49 \pm 2.09$ & $4.0-6.2$ \\
\hline Creatinine (Cr; mg/dL) & $|.36 \pm 8.4|$ & $0.5-1.2$ \\
\hline $\begin{array}{l}\text { Creatinine clearance } \\
(\mathrm{CrCl} ; \mathrm{mL} / \mathrm{min})\end{array}$ & $117.97 \pm 522.23$ & $88-137$ \\
\hline $\begin{array}{l}\text { Aspartate transaminase } \\
\text { (AST; U/L) }\end{array}$ & $23.23 \pm 21.80$ & $0.0-50.0$ \\
\hline $\begin{array}{l}\text { Alanine transaminase } \\
\text { (ALT; } \mathrm{mlU} / \mathrm{mL} \text { ) }\end{array}$ & $21.7 \mathrm{I} \pm 20.14$ & $0.0-50.0$ \\
\hline Hemoglobin $(g / d L)$ & $13.22 \pm 7.54$ & $11.0-16.5$ \\
\hline $\begin{array}{l}\text { Thyroid-stimulating } \\
\text { hormone (TSH, } \mathrm{mlU} / \mathrm{mL})\end{array}$ & $2.58 \pm 3.01$ & $4.0-0.22$ \\
\hline
\end{tabular}


Table 5 Number of DRPs according to clinical characteristics of patients

\begin{tabular}{|c|c|c|}
\hline Clinical variable & DRPs (mean \pm SD) & $P$-value ${ }^{a}$ \\
\hline \multicolumn{3}{|l|}{$\mathrm{Age}^{\mathrm{b}}$} \\
\hline$\leq 57$ & $10.17 \pm 6.2$ & $<0.001$ \\
\hline$>57$ & $11.76 \pm 6.1$ & \\
\hline \multicolumn{3}{|l|}{ Sex } \\
\hline Male & $11.02 \pm 6.0$ & 0.690 \\
\hline Female & $10.92 \pm 6.3$ & \\
\hline \multicolumn{3}{|l|}{ Social status } \\
\hline $\begin{array}{l}\text { Single (never married, } \\
\text { divorced, and widowed) }\end{array}$ & $10.33 \pm 6.1$ & 0.007 \\
\hline Married & $1 \mathrm{I} .1 \mathrm{I} \pm 6.2$ & \\
\hline \multicolumn{3}{|l|}{ Educational level } \\
\hline High school or less & $11.45 \pm 6.3$ & $<0.001$ \\
\hline More than high school & $9.58 \pm 5.8$ & \\
\hline \multicolumn{3}{|l|}{ Occupation } \\
\hline Nonmedical & $10.96 \pm 6.2$ & 0.820 \\
\hline Medical & $11.20 \pm 6.0$ & \\
\hline \multicolumn{3}{|l|}{ Health insurance } \\
\hline Yes & $11.19 \pm 6.3$ & $<0.001$ \\
\hline No & $8.16 \pm 5.5$ & \\
\hline
\end{tabular}

Notes: anpaired $t$-test was used to compare the mean of DRPs. ${ }^{\text {DMedian age of }}$ the study sample $=57$ years.

Abbreviations: DRPs, drug-related problems; SD, standard deviation.

obstructive pulmonary disease were associated with lower numbers of DRPs.

\section{Discussion}

This study is the first to evaluate DRPs in outpatient clinics in Jordan and the Middle East and North African regions. Current results indicated an average of eleven DRPs per outpatient with chronic disease in Jordanian hospitals. The most commonly identified DRPs were a need for additional or more frequent monitoring, a problem in patients' adherence to self-care activities or nonpharmacological therapy, and the patient was not given instruction in or did not understand nonpharmacological therapy or self-care advice.

The need for additional or more frequent monitoring was found to be the most commonly encountered DRPs in a study about implementing collaborative medication management services in Australia. ${ }^{24}$ This is in agreement with the results of the current study. Additionally, results of the current study showed that DRPs related to adherence to self-care activities represent $13.45 \%$ of total encountered DRPs. This is consistent with a study done among patients with heart failure in Spain, where nonadherence rate to self-care activities of $\sim 14 \%$ was reported..$^{25}$ Additionally, in a study evaluating hospitalized patients in Jordan, the rate of DRPs due to need for consultation and need for additional diagnostic tests was
Table 6 Number of DRPs according to clinical characteristics of patients

\begin{tabular}{|c|c|c|}
\hline Clinical variable & DRPs (mean \pm SD) & $P$-value ${ }^{a}$ \\
\hline \multicolumn{3}{|l|}{ Hypertension } \\
\hline Yes & $11.86 \pm 6.0$ & $<0.001$ \\
\hline No & $8.40 \pm 6.0$ & \\
\hline \multicolumn{3}{|l|}{ DM } \\
\hline Yes & $14.52 \pm 5.6$ & $<0.001$ \\
\hline No & $7.08 \pm 4.1$ & \\
\hline \multicolumn{3}{|l|}{ Dyslipidemia } \\
\hline Yes & $13.34 \pm 6.1$ & $<0.001$ \\
\hline No & $9.51 \pm 5.8$ & \\
\hline \multicolumn{3}{|c|}{ Ischemic heart disease } \\
\hline Yes & $13.06 \pm 6.1$ & $<0.001$ \\
\hline No & $10.10 \pm 6.0$ & \\
\hline \multicolumn{3}{|c|}{ Cardiac catheterization } \\
\hline Yes & $12.80 \pm 6.3$ & $<0.001$ \\
\hline No & $10.40 \pm 6.2$ & \\
\hline \multicolumn{3}{|l|}{ Asthma } \\
\hline Yes & $7.58 \pm 5.86$ & $<0.001$ \\
\hline No & $11.57 \pm 5.98$ & \\
\hline \multicolumn{3}{|l|}{ Heart failure } \\
\hline Yes & $12.54 \pm 6.3$ & $<0.001$ \\
\hline No & $10.81 \pm 6.2$ & \\
\hline \multicolumn{3}{|l|}{ Cholecystectomy } \\
\hline Yes & $11.78 \pm 5.8$ & $0.07 I$ \\
\hline No & $11.03 \pm 6.3$ & \\
\hline \multicolumn{3}{|l|}{ Hypothyroidism } \\
\hline Yes & $11.90 \pm 5.4$ & 0.056 \\
\hline No & $10.90 \pm 6.3$ & \\
\hline \multicolumn{3}{|l|}{ Gout } \\
\hline Yes & $12.22 \pm 5.1$ & 0.013 \\
\hline No & $10.90 \pm 6.2$ & \\
\hline \multicolumn{3}{|l|}{ COPD } \\
\hline Yes & $8.35 \pm 3.4$ & $<0.001$ \\
\hline No & $11.07 \pm 6.2$ & \\
\hline
\end{tabular}

Note: anpaired $t$-test was used to compare the mean of DRPs in patients who have the clinical condition (eg, hypertension and DM) versus those who do not. Abbreviations: COPD, chronic obstructive pulmonary disease; DRPs, drug-related problems; SD, standard deviation; DM, diabetes mellitus.

similar to the ones reported in the current study..$^{16}$ Finally, the rate of DRPs related to patients not given instruction in or do not understand important information about their medication or nonpharmacological intervention was found to be similar to a Malaysian study that evaluated DRPs in inpatients with diabetes. ${ }^{26}$ Other not common DRPs in this current study, such as more effective drug is available, current drug is contraindicated, dosage regimen issue, and drug use without indication, were also found to be least common in other studies. ${ }^{16,26}$

The current results indicated the association between the presence of DRPs and certain medical conditions such as hypertension, diabetes mellitus, dyslipidemia, ischemic heart 
disease, cardiac catheterization, heart failure, and gout. This is consistent with the results of a previous study that found the medications used in the management of mentioned conditions (eg, diuretics, digoxin, insulin, and oral antidiabetics.) as risk factors for DRPs among patients. ${ }^{27}$ On the other hand, the presence of asthma and chronic obstructive pulmonary disease was associated with significantly fewer numbers of DRPs. This could be related to multiple local campaigns related to the assessment of DRPs among respiratory patients, especially those pertaining to inhaler device techniques, which is the major source of DRPs among these patients. ${ }^{28}$

This study has certain strengths such as its large sample size, its coverage of several hospitals representing different aspects of health care in Jordan, and its coverage of outpatient settings, which is an area that has limited literature compared to inpatient settings. Yet, this study has some weaknesses such as aiming to only describe the current situation of DRPs without doing actual interventions, assessing the acceptance rate of other health care providers to these interventions, and assessing the extent of implementation of interventions and their impact on patient health outcomes. These points were not attempted because clinical pharmacy services are not implemented in most of the governmental hospitals in Jordan, and this study is expected to provide corner stone evidence for decision makers to show the need for implementing clinical pharmacy services. Future work is suggested to cover the above points and to fully evaluate clinical pharmacy model services, which will provide more evidence to ensure the success and benefits of implementation of clinical pharmacy services in reducing DRPs and improving patient health outcomes.

\section{Conclusion}

Implementation of clinical pharmacy services is a recommended strategy to identify DRPs in Jordanian health settings.

\section{Funding}

This project was supported by The Scientific Research Funds (project number MPH/2/04/2011) of the Ministry of Higher Education and Scientific Research, Amman, Jordan.

\section{Disclosure}

The authors report no conflicts of interest in this work.

\section{References}

1. Hohmann C, Radziwill R, Klotz JM, Jacobs AH. Health-related quality of life after ischemic stroke: the impact of pharmaceutical interventions on drug therapy (pharmaceutical care concept). Health Qual Life Outcomes. 2010;8:59.
2. Chiatti C, Bustacchini S, Furneri G, et al. The economic burden of inappropriate drug prescribing, lack of adherence and compliance, adverse drug events in older people: a systematic review. Drug Saf. 2012;35(suppl 1):73-87.

3. Gosch M, Roller RE. [Multiple drug therapy - a challenge for an aging society]. Wien Med Wochenschr. 2010;160(11-12):261-263.

4. Cipolle RJ, Strand L, Morley P. Pharmaceutical Care Practice: The Clinician's Guide. 2nd ed. New York: McGraw-Hill; 2004. ISBN: 9780071362597.

5. Basger BJ, Moles RJ, Chen TF. Development of an aggregated system for classifying causes of drug-related problems. Ann Pharmacother. 2015;49(4):405-418

6. Lenander C, Elfsson B, Danielsson B, Midlov P, Hasselstrom J. Effects of a pharmacist-led structured medication review in primary care on drug-related problems and hospital admission rates: a randomized controlled trial. Scand J Prim Health Care. 2014;32(4):180-186.

7. Silva C, Ramalho C, Luz I, Monteiro J, Fresco P. Drug-related problems in institutionalized, polymedicated elderly patients: opportunities for pharmacist intervention. Int J Clin Pharm. 2015;37(2): 327-334.

8. Richardson TE, O'Reilly CL, Chen TF. Drug-related problems and the clinical role of pharmacists in inpatient mental health: an insight into practice in Australia. Int J Clin Pharm. 2014;36(5):1077-1086.

9. Vijayakumar A, Sharon EV, Teena J, Nobil S, Nazeer I. A clinical study on drug-related problems associated with intravenous drug administration. J Basic Clin Pharm. 2014;5(2):49-53.

10. Alghamdy MS, Randhawa MA, Al-Wahhas MH, Al-Jumaan MA. Admissions for drug-related problems at the Emergency Department of a University Hospital in the Kingdom of Saudi Arabia. J Family Community Med. 2015;22(1):44-48.

11. Somers A, Petrovic M. [Major drug related problems leading to hospital admission in the elderly]. J Pharm Belg. 2014;2:34-38.

12. Kheir N, Awaisu A, Sharfi A, Kida M, Adam A. Drug-related problems identified by pharmacists conducting medication use reviews at a primary health center in Qatar. Int J Clin Pharm. 2014;36(4): 702-706.

13. de Lyra DP, Kheir N, Abriata JP, da Rocha CE, Dos Santos CB, Pela IR. Impact of pharmaceutical care interventions in the identification and resolution of drug-related problems and on quality of life in a group of elderly outpatients in Ribeirao Preto (SP), Brazil. Ther Clin Risk Manag. 2007;3(6):989-998.

14. Hanlon JT, Schmader KE, Ruby CM, Weinberger M. Suboptimal prescribing in older inpatients and outpatients. J Am Geriatr Soc. 2001;49(2): 200-209.

15. Gheewala PA, Peterson GM, Curtain CM, Nishtala PS, Hannan PJ, Castelino RL. Impact of the pharmacist medication review services on drug-related problems and potentially inappropriate prescribing of renally cleared medications in residents of aged care facilities. Drugs Aging. 2014;31(11):825-835.

16. AbuRuz SM, Bulatova NR, Yousef AM, Al-Ghazawi MA, Alawwa IA, Al-Saleh A. Comprehensive assessment of treatment related problems in hospitalized medicine patients in Jordan. Int J Clin Pharm. 2011;33(3): 501-511.

17. Kempen TG, van de Steeg-van Gompel CH, Hoogland P, Liu Y, Bouvy ML. Large scale implementation of clinical medication reviews in Dutch community pharmacies: drug-related problems and interventions. Int J Clin Pharm. 2014;36(3):630-635.

18. Kjeldsen LJ, Birkholm T, Fischer H, et al. Characterization of drugrelated problems identified by clinical pharmacy staff at Danish hospitals. Int J Clin Pharm. 2014;36(4):734-741.

19. Braund R, Coulter CV, Bodington AJ, et al. Drug related problems identified by community pharmacists on hospital discharge prescriptions in New Zealand. Int J Clin Pharm. 2014;36(3):498-502.

20. Al-Arifi M, Abu-Hashem H, Al-Meziny M, Said R, Aljadhey H. Emergency department visits and admissions due to drug related problems at Riyadh military hospital (RMH), Saudi Arabia. Saudi Pharm J. 2014;22(1):17-25. 
21. Basheti IA, Qunaibi EA, Bulatova NR, Samara S, AbuRuz S. Treatment related problems for outpatients with chronic diseases in Jordan: the value of home medication reviews. Int J Clin Pharm. 2013;35(1): 92-100.

22. AbuRuz SM, Bulatova NR, Yousef AM. Validation of a comprehensive classification tool for treatment-related problems. Pharm World Sci. 2006;28(4):222-232.

23. AbuRuz SM. The case for evidence based pharmaceutical care. Res Social Adm Pharm. 2009;11(3):e146-e147.

24. Gilbert AL, Roughead EE, Beilby J, Mott K, Barratt JD. Collaborative medication management services: improving patient care. Med J Aust. 2002;177(4):189-192.

25. Gastelurrutia P, Benrimoj SI, Espejo J, Tuneu L, Mangues MA, BayesGenis A. Negative clinical outcomes associated with drug-related problems in heart failure (HF) outpatients: impact of a pharmacist in a multidisciplinary HF clinic. J Card Fail. 2011;17(3):217-223.
26. Zaman Huri H, Fun Wee H. Drug related problems in type 2 diabetes patients with hypertension: a cross-sectional retrospective study. $B M C$ Endocr Disord. 2013;13:2.

27. Kaufmann CP, Stampfli D, Hersberger KE, Lampert ML. Determination of risk factors for drug-related problems: a multidisciplinary triangulation process. BMJ Open. 2015;5(3):e006376.

28. Khassawneh BY, Al-Ali MK, Alzoubi KH, et al. Handling of inhaler devices in actual pulmonary practice: metered-dose inhaler versus dry powder inhalers. Respir Care. 2008;53(3):324-328.

\section{Publish your work in this journal}

Therapeutics and Clinical Risk Management is an international, peerreviewed journal of clinical therapeutics and risk management, focusing on concise rapid reporting of clinical studies in all therapeutic areas, outcomes, safety, and programs for the effective, safe, and sustained use of medicines. This journal is indexed on PubMed Central, CAS,
EMBase, Scopus and the Elsevier Bibliographic databases. The manuscript management system is completely online and includes a very quick and fair peer-review system, which is all easy to use. Visit http://www.dovepress.com/testimonials.php to read real quotes from published authors.

Submit your manuscript here: http://www.dovepress.com/therapeutics-and-clinical-risk-management-journal 